\title{
Eruptions triggered by volatiles \\ buoyancy: a way to mobilize mush without reheating?
}

\author{
CATHERINE J. ANNEN ${ }^{1}$, ALAIN BURGISSER ${ }^{2}$ AND \\ VIRGINIE PINEL ${ }^{2}$ \\ ${ }^{1}$ Institute of Geophysics, Czech Academy of Sciences \\ ${ }^{2}$ ISTerre
}

Presenting Author: annen@ig.cas.cz

The overpressure induced by volatiles release is often invoked as a cause of magma chamber failure and eruption. We used numerical simulation to model the exsolution of $\mathrm{H}_{2} \mathrm{O}$ from a growing and solidifying silicic magma chamber. $\mathrm{H}_{2} \mathrm{O}$ is incompatible and concentrates in the melt. When saturation is exceeded, $\mathrm{H}_{2} \mathrm{O}$ exsolves and forms a separate supercritical fluid phase. The rocks that surround magma chambers are likely to be visco-elastic so that the rate of volume increase rather than the volume increase per se is determinant in causing failure. Our simulations show that the rate of $\mathrm{H}_{2} \mathrm{O}$ release is too slow to induce fractures in the magma chamber walls. Indeed, the exsolution of $\mathrm{H}_{2} \mathrm{O}$ is controlled by crystallization, which itself is controlled by cooling and heat diffusion. However, we also find that the channeling of $\mathrm{H}_{2} \mathrm{O}$ through the mush that surrounds the chamber results in the formation of $\mathrm{H}_{2} \mathrm{O}$-rich layers in the chamber's roof and walls. The buoyancy exerted by the accumulated $\mathrm{H}_{2} \mathrm{O}$ is high enough to fracture the surrounding rocks. Eruptions triggered by the buoyancy of volatiles trapped in the solidifying part of the chamber would mobilize both the mush that surrounds the chamber and the liquid magma in the chamber. It explains the spread of ages commonly observed in crystal cargos. According to our model, mush mobilization and eruption by volatile accumulation are more likely to occur during the cooling of a magma body and do not require new addition of heat. 